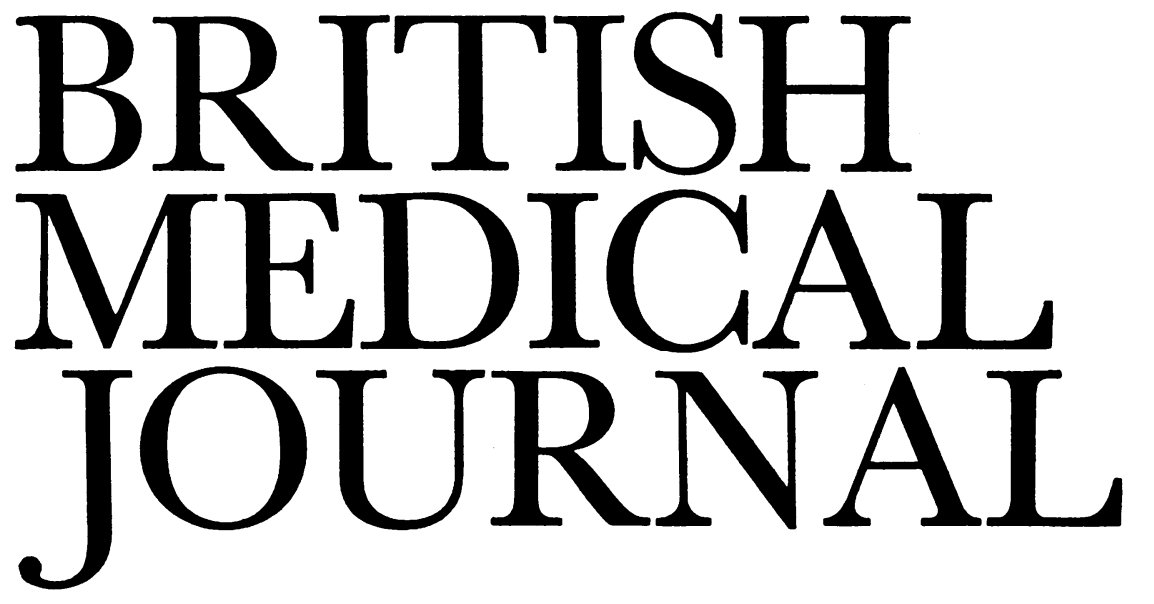

LONDON, SATURDAY 19 APRIL 1980

\title{
School pregnancies
}

From 1974 to 1976 in England and Wales 14739 schoolgirls below the age of 16 became pregnant and 10273 of these pregnancies were legally terminated. ${ }^{12}$ Against the 1740000 births and 317000 legal abortions that took place nationally during the same period these numbers seem small. Nevertheless, the problems that stem from pregnancy at such an early age are especially distressing for the girl, for her family, and for those in the medical, social, and educational services who have to deal with the immediate and long-term effects. Some of the consequences are well established; information on others-many others-is either scanty or non-existent.

Compared with older teenagers and women up to the age of 35 , these young girls are more likely to have complicated pregnancies: morbidity and mortality rates are higher for the young mothers and their babies. ${ }^{3-8}$ Both social deprivation and physical and psychological immaturity are likely to play some part in this poor reproductive performance, but the relative importance of each is uncertain.

National figures show that gynaecologists tend to terminate most of the pregnancies, but one difficulty is that the very young often delay their request for abortion. In 1968 and 1969-immediately after the Abortion Act-49\% of the abortions carried out on girls under the age of 16 were beyond 13 weeks' gestation; the comparable figure for girls aged 16 to 19 was $40 \%$. By 1975 the figures had dropped respectively to $30 \%$ and $25 \% .{ }^{9}$ This trend towards earlier termination in the very young is likely to reduce the associated risks, but the hazards are still remarkably ill understood. The cervix and cervical canal in a girl aged 14 or 15 with a 10 weeks' pregnancy may be quite small, firm, and tightly closedvery different from the larger, softer, and more patulous cervix found in older women. Russell ${ }^{10}$ has reported that in the course of therapeutic abortion, in spite of all care, cervical trauma is more likely to occur in the youngest patients. The full meaning of such damage in terms of leucorrhoea, dysmenorrhoea, dyspareunia, and possible adverse effects on future reproduction is undetermined.

What of the wider consequences, the impact of the pregnancy on the girl and on her family, and what of the child when the pregnancy continues and a baby is born? Some of these girls are much upset by pregnancy, ${ }^{11} 13$ and one review of the experience of a group of mothers under the age of 18 reported that the risk of later attempts at suicide is relatively high. ${ }^{14}$ Brandon ${ }^{15}$ found an association between early motherhood, a poor relationship between baby and mother, and baby battering.

A recent survey of the circumstances of some 500 pregnant schoolgirls in England and Wales ${ }^{16}$ showed that most $(71 \%)$ of the girls lived at home throughout the whole of their pregnancy, and $66 \%$ returned home after the birth. This arrangement is likely to offer the girl and her child maximum emotional and practical support, but it may be otherwise. Russell ${ }^{1718}$ found examples of tension and discord within families that could lead to disruption of the whole family unit. We know too little of what these pregnancies mean for the families concerned. Again, we have sparse information on what happens to the babies born to these young mothers, and especially on their physical and emotional development as they grow up. How many are deprived or disadvantaged and does this depend on whether they remain within their own family units or are fostered or adopted ? Given the immaturity of the fathers of most of these babies, does marriage (one-third of married 16 year olds in 1977 were married before the birth of their child) help or worsen matters that are already difficult enough?

Pregnancy in their pupils is rightly a matter of concern to schools and teachers, for loss or disruption of education is surely one of the most serious consequences of pregnancy at this age. Responses to a questionnaire sent to over 300 schools in England and Wales showed widespread compassion for these young girls and the problems they and their families face. In spite of the apparent willingness of teachers to be helpful, most of the schoolgirls who became mothers during the three academic years 1973-6 suffered considerable loss of education: $22 \%$ had left school by the end of the first trimester and $74 \%$ by the end of the fifth month. Furthermore, $61 \%$ of the girls who left school early received no education whatsoever between then and the birth of their baby. After the birth $53 \%$ of girls below the statutory school leaving age did not return to school and only $8 \%$ of them received any other form of education at all. At the time the questionnaire was completed only $41 \%$ of the girls who had planned to sit examinations had done so.

The known consequences of pregnancy in schoolgirls are all to the disadvantage of the girls, their babies, their families, and society. The likelihood is that the picture would look 
even worse if we knew more of the long-term effects, and there is ample scope for well-organised research. The medical issues are probably more clearly defined and easier to examine and assess than the wider and more complex social and educational implications.

Above all it is prevention that matters, and medicine has a clear contribution to make through family planning programmes directed specifically to the needs of the young, with attention drawn to the responsibilities that come with sexual activity. Again, it is for doctors to point out the possible medical sequelae of sexual activity at this age. But the contribution of others may be more important. In her book The Vulnerable Generation Elizabeth Manners ${ }^{19}$ pleads for a return to those values and standards which have long held families together and have contributed to the stability of society: discipline, truth, service to the community, consideration for others, a sense of responsibility, and chastity before and fidelity after marriage. The young, in her view, need to be protected against the twin onslaughts of materialism and commercial exploitation-a daunting task in the face of what is beamed at them from bill hoardings, magazines, the television screen, and the stage, not to mention the behaviour of some of their pop idols.

1 Office of Population Censuses and Surveys. Abortion statistics 1974, 1975, and 1976. London: HMSO, 1977, 1978, and 1979.

2 Office of Population Censuses and Surveys. Birth statistics 1974, 1975, and 1976. London: HMSO, 1977, 1978, 1979.

3 Tietze C. Maternal mortality excluding abortion mortality. World Health Statistics Report 1977;30(4):312-39.

4 Lambert P. Perinatal mortality: social and environmental factors. Population Trends 1976 ;no $4: 4-11$.

- British births. 1970, vol 1: The first week of life. London: Heinemann Medical, 1975.

- Puffer RR, Serrano CV. Birthweight, maternal age and birth order. Pan American Health Organisation. Scientific Publication no 294, 1975.

7 Reports on confidential enquiries into maternal deaths in England and Wales. London: HMSO, 1961-75.

Beschamps JP, Valantin G. F Biosoc Sci 1978;suppl 5:101-16

- Rothman D, Capell P. Teenage pregnancy in England and Wales: some demographic and medico-social aspects. F Biosoc Sci 1978;suppl 5: 65-83.

${ }^{10}$ Russell JK. Sexual activity and its consequences in the teenager. Clin Obstet Gynaecol 1974;1:683-97.

11 Scher J, Utian WH. Teenage pregnancy-an inter-racial study. $\mathfrak{f}$ Obstet Gynaecol Br Commonwealth 1970;77:259-62.

12 Pugh TF, Jerath BK, Schmidt WM, Reed RB. Rates of mental disease and related to childbearing. $N$ Engl f Med 1963;268:1224-9.

13 Whitlock FA, Edwards JE. Pregnancy and attempted suicide. Compr Psychiatry 1968;9:1-12.

14 Gabrielson IW, Klerman LV, Currie JB, Tyler NC, Jekel JF. Suicide attempts in a population pregnant as teen-agers. Am $\mathcal{F}$ Public Health $1970 ; 60: 2289-95$.

16 Brandon S. An epidemiological study of eating disturbances. $\mathcal{F}$ Psychosom Res $1970 ; 14: 253-7$

16 Joint Working Party on Pregnant Schoolgirls and Schoolgirl Mothers. Pregnant at school. London: National Council for One Parent Families, 1979.

17 Russell JK. Pregnancy in the young teenager. Lancet $1969 ; \mathrm{i}: 365-6$.

18 Russell JK. Pregnancy in the young teenager. Practitioner 1970;204:401-5.

19 Manners E. The vulnerable generation. London: Cassell, 1971.

\section{Mild hypertension}

Blood pressure is a continuous variable. Moreover, since the risks associated with raised blood pressure are also graded, it may be difficult to decide clinically what constitutes "hypertension" and by implication which patients should have antihypertensive treatment. In young and middle-aged adults the therapeutic decision is most difficult in the diastolic pressure range $90-104 \mathrm{~mm} \mathrm{Hg}$. The often quoted Veterans
Administration Study ${ }^{1}$ showed a beneficial outcome with drug treatment in those with diastolic blood pressures above $104 \mathrm{~mm} \mathrm{Hg}$. The dearth of information on hypertensive patients (of both sexes) with milder hypertension has prompted the setting up of the Medical Research Council trial on mild hypertension, ${ }^{2}$ but the results will not be available for some time. Meanwhile the findings of two recently reported trials are of interest.

The United States Hypertension Detection and Follow up Programme ${ }^{34}$ has recently reported a five-year comparison of the results of conventional management of hypertension with that of an "augmented convenient programme," which meant attendence at special clinics run by the programme, and included advice on lifestyle, provision of free medications, and an aggressive approach to the control of blood pressure. Control was, indeed, better and overall mortality was $17 \%$ lower in those who attended the special clinic. In patients with mild hypertension (diastolic $95-104 \mathrm{~mm} \mathrm{Hg}$ ) the benefit of the special follow-up was even more dramatic-a $20 \%$ reduction in mortality. The authors of the report reasonably state, "The systematic management of hypertension has a great potential for reducing mortality for the large number of people with high blood pressure in the population including those with mild hypertension." Since, however, the study compared the outcome of two forms of health care in a unique social setting its results cannot readily be applied to other populations. Peart and Miall $^{5}$ have pointed out that many patients included had been having treatment before the trial began, so that their blood pressures would have been higher before any treatment began-in other words, their hypertension was not as mild as it seemed. Furthermore, disproportionately much of the improved outcome was attributable to that occurring in black patients, who made up only $45 \%$ of the group.

The initial results of the Australian Therapeutic Trial in Mild Hypertension ${ }^{6}$ also suggest that treatment is beneficial. Patients with diastolic blood pressures over $100 \mathrm{~mm} \mathbf{H g}$ who had adhered to treatment had a mortality one-third that observed in a control group treated with placebos. No benefit from treatment was found in patients with diastolic pressures between 95 and $100 \mathrm{~mm} \mathrm{Hg}$, but the Australian group advised that such patients should be kept under periodic assessment.

How do these studies help the practising clinician? Certainly it will take time for a clear consensus to appear about the implications of the Hypertension Detection Follow up Programme study, and the results from the Australian study are labelled "initial." Nevertheless, healthy middle-aged patients will probably now be treated for milder degrees of hypertension than was formerly the case. If the MRC trial confirms the general conclusions of the Hypertension Detection Follow up Programme, patient with diastolic pressures of $90 \mathrm{~mm} \mathrm{Hg}$ and greater will warrant treatment. At present a reasonable compromise is for doctors to treat patients with confirmed diastolic pressures greater than $95 \mathrm{~mm} \mathrm{Hg}$. The presence of complications, an unfavourable family history, or a raised systolic pressure may well lower the threshold for intervention.

There are still many unanswered questions. How relevant is the Hypertension Detection Follow up Programme study to other populations and other health care systems? What is the level of blood pressure (systolic as well as diastolic) at which the snags of long-term treatment outweigh the risks of hypertension? What should be the goal of treatment? The MRC study group carries the burden of writing the next chapter in this continuing saga. 